\title{
درجة امتلاك معلّمات المرحلة الأساسيّة الدُّنيا في مدينة عمّان لمهارات الاستماع للقرآن الكريه
}

\author{
عيسلى خليل الحسنات \\ كلية العلوم التربوية- الجامعة العربية المفتوحة- الأردن \\ i_hasanat@aou.edu.jo
}

\author{
مجدي سليمان المشاعلة \\ كلية العلوم التربوية- الجامعة العربية المفتوحة- الأردن \\ m_mashaleh@aou.edu.jo
}

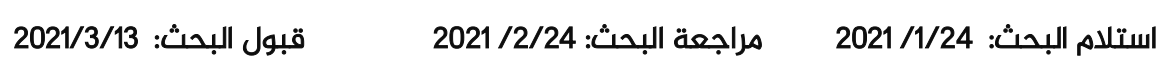

DOI: https://doi.org/10.31559/EPS2021.10.1.6 


\author{
مجدي سليمان المشاعلة \\ كلية العلوم التربوية- الجامعة العببية المفتوحة- الأردن \\ m_mashaleh@aou.edu.jo \\ عيسى خليل الحسنات \\ كلية العلوم التربوية- الجامعة العربية المفتوحة- الأردن \\ i_hasanat@aou.edu.jo
}

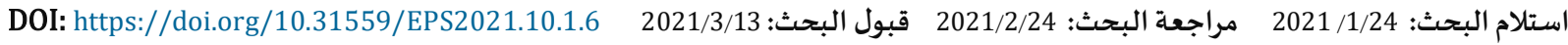

الخص: التعليمية والمؤهل العلمي في امتلاك هذه المهارات. وتكوّن مجتمع الدراسة من المعلمات اللواتي يدرّسنَنَ هذه المرحلة في مديرية تربية قصبة

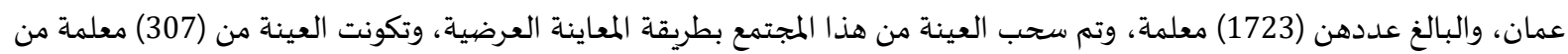

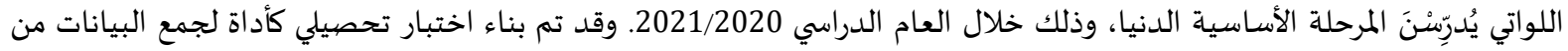

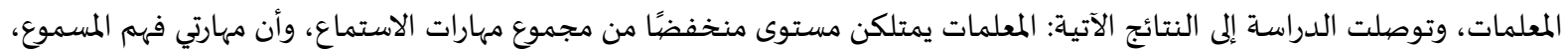

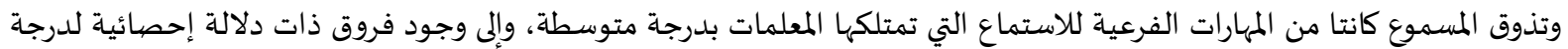

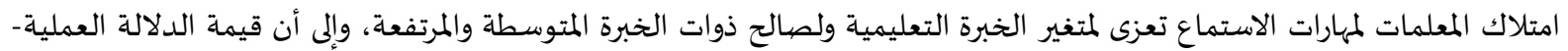

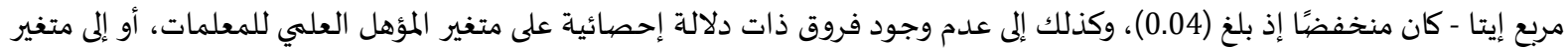
التفاعل بين الخبرة التعليمية والمؤهل العلمي. وقد قدمت الدراسة بناء على النتائج التي توصلت إلهها مجموعة من التوصيات، منها: الاهتمام بإعداد المزيد من الاختبارات لقياس مدى امتلاك المعلمين لمهارات التعليم الضرورية لهم. الكلمات المفتاحية: درجة امتلاك المعلمين؛ معلمي المرحلة الأساسية الدنيا؛ المهارة؛ الاستماع؛ مهارات الاستماع للقرآن الكريم.

يُعد المعلم حجر الأساس في العملية التعليمية، وتشكل معرفة المعلم للمقرر الذي يدرساه ولأصول تدريسـه عنصرًا أساسيًا في الإطار المرجعي

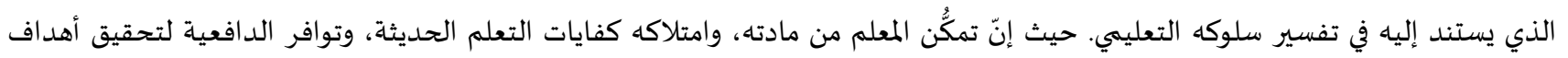

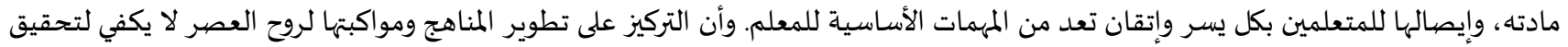

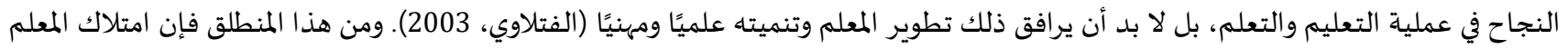

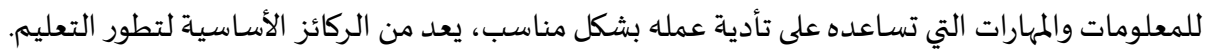


ولهذا الغرض فقد أكدت الدراسات، أن نجاح التدريس يتوقف بشكل أساسي على وجود معلم معد إعدادًا جيدًا ومسلحًا علميًا ومهنيًا وثقافيًا،

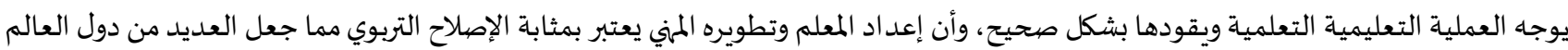

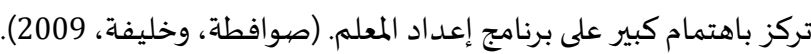

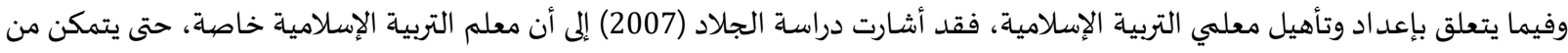

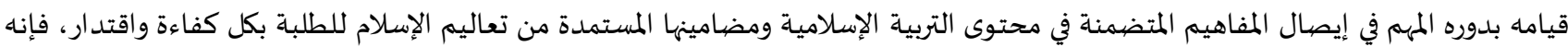
يجب عليه امتلاك كفايات التدريس الفاعلة. وأما دراسة هندي (2002) فقد أشارت كذلك إلى أن برامج إعداد معلم التربية الإسلامية تفتقر إلى فلسفة

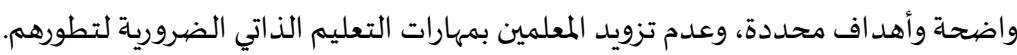

1.1

تعد مهارة الاستماع من المهارات المتأصلة في القرآن الكريم، ومن الوسائل الأساسية في تلقيه، وهي الوسيلة التي تعلم بها رسول الله - صلى الله عليه وسلم- القرآن الكريم من جبريل-عليه السلام-، وعلم بها أصحابه -رضي الله عنهم-، ولقد كانت القاعدة المتبعة منذ عهد الرسول -صهلى الله عليه

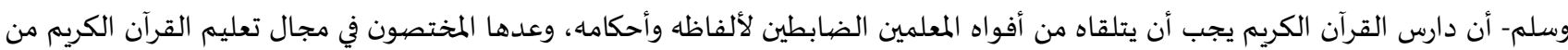
الخطوات الأولى في تلقي القرآن الكريم وأطلقوا عليها اسم "التلقي الشفهي" للقرآن آنس الكريهم. وبناء على خبرة الباحثين وتخصصيهما في تدريب معلمي المرحلة الأساسية وتطوير قدراتهم في مجال الكفايات التدريسية فقد كاندانها يشعران

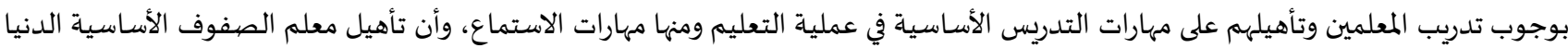

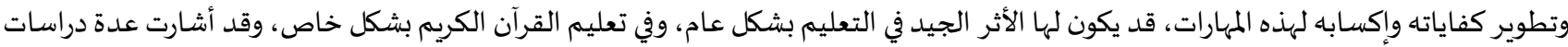

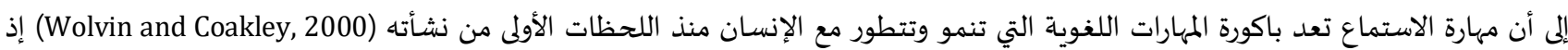

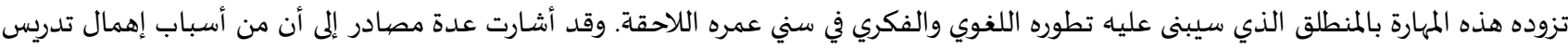

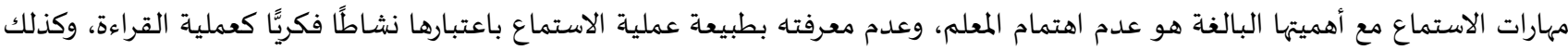

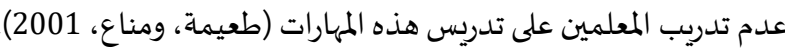

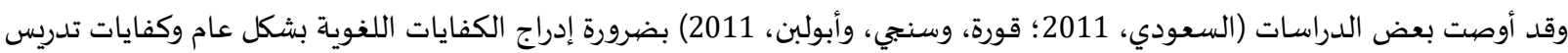
مهارات الاستماع بشكل خاص في برامج تدريب المعلمين من خلال الدروس والمشاغل والتعليم المصغر، وأن تكون متضمنة في استمارة الزيارة الصفية، ودليل المعلم. وهذا مما يفرض على كليات التربية ووزارات التربية والتعليم أن تهتم باء، وأن يكون المعلم قدوة طيبة للطلبة في امتلاك مهارات الاستماع.

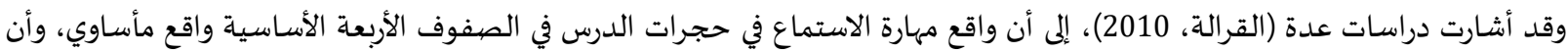

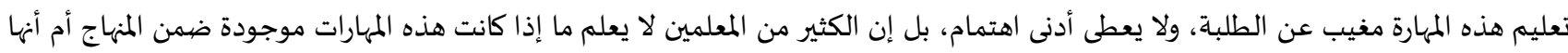

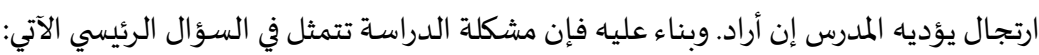

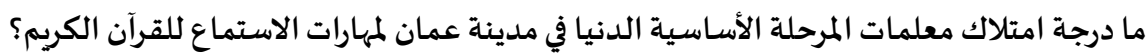

تسعى هذه الدراسة للإجابة عن الأسئلة الفرعية الآتية: ما درجة امتلاك معلمات المرحلة الأساسية الدنيا لمهارات الاستماع للقرآن الكريم؟ الاسنيه الهرعيه

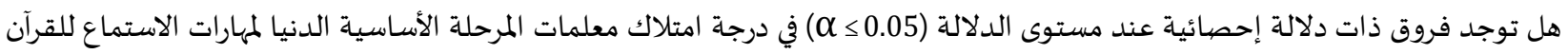
الكريم، تعزى لمتغير الخبرة التعليمية، أو المؤهل العلمي، أو التفاعل بينهما؟

3.1 انبثق عن السؤال الثاني الفروض الآتية:

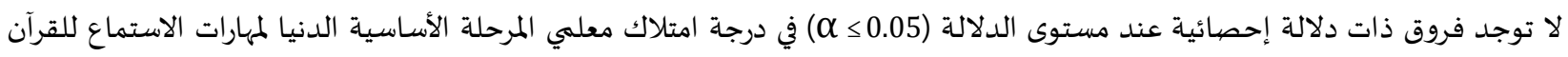

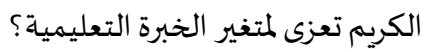
لا توجد فروق ذات دلالة إحصائية عند مستوى الدلالة (150.05) في درجة امتلاك معلمي المرحلة الأساسية الدنيا لمهارات الاستماع للقرآن الكريم تعزى لمتغير المؤهل العلمي؟

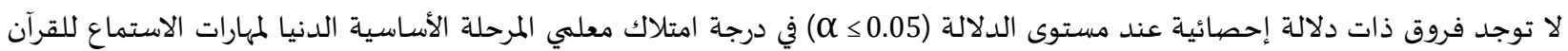
الكريم تعزى للتفاعل بين متغيري الخبرة والمؤهل العلمي؟ 


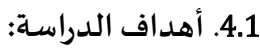

هدفت الدراسة الحالية إلى: - مداه:

تعرف درجة امتلاك معلمات المرحلة الأساسية الدنيا لمهارات الاستماع للقرآن الكريم.

الكشف عن ترتيب مهارات الاستماع التي تمتلكها المعلمات في تدريس القرآن الكريم.

الكشف عن الفروق في درجة امتلاك معلمات المرحلة الأساسية الدنيا لمهارات الاستماع للقرآن الكريم، تبعًا لمتغيرات الخبرة التعليمية، والمؤهل

العلمي، والتفاعل بينهما.

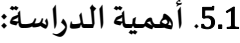

تكتسب هذه الدراسة أهميتها من أنها:

تتناول مهارات الاستماع لتعلم القرآن الكريم في المرحلة الأسـاسية الدنيا التي تعد من أهم المراحل التعليمية لكونها مرحلة بناء المهارات الأساسية للتعلم.

قد تسهم هذه الدراسة في تطوير الإشراف التربوي من خلال إعداد اختبار لتقويم أداء معلمات المرحلة الأسـاسية الدنيا في مدى امتلاكه لمهارات الاستماع لتعلم القرآن الكريهم.

تسلط الضوء على معلمة المرحلة الأساسية الدنيا باعتبارها من الفاعلين في إكساب وتنمية مهارات الاستماع لتعلم القرآن الكريم لدى طلبة المرحلة الأساسية الدنيا.

توجه أنظار القائمين على برامج إعداد معلمات المرحلة الأساسية الدنيا إلى ضرورة إكساب الطلبة من معلمات المرحلة الأساسية الدنيا لمهارات الاستماع اللازمة لتعليم القرآن الكريم.

من الناحية النظرية تحاول هذه الدراسة التعرف إلى مدى مساهمة عوامل الخبرة التعليمية والمؤهل العلمي في درجة امتلاك مهارات الاستماع للقرآن الكريم. المساعدة على تقويم مخرجات التعلم لكليات التربية، وما يلزم لتفعيل برنامج إعداد المعلمين. 6.1. حدود ومحدددات الدراسـة:

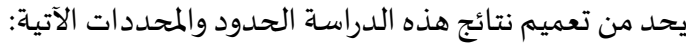
الحدود البشرية: اقتصرت حدود هذه الدراسة البشرية على عينة من المعلمات اللواتي يدرّسنَْ الصفوف الثلاثة الأولى في المرحلة الأساسية الدنيا (الصف الأول، والثاني، والثالث) الحدود الموضوعية: حيث اقتصرت الدراسة الحالية على مهارات الاستماع لتعلم القرآن الكريم التي تضمنها الاختبار الذي أعده الباحثان. الحدود المكانية: اقتصرت الدراساة على معلمات المرحلة الأساسية الدنيا في المدراس الأساسية بمديرية لواء قصبة عمان. الحدود الزمانية: طبقت الدراسة خلال الفصل الدراسي الأول للعام الدراسي 2021/2020

7.1. التعريفات الإجر ائية: اشتملت هذه الدراسة على مجموعة من المفاهيم والمصطلحات، المهرئ التي يعتقد الباحثان بضرورة تعريفها وتحديدها، وفقاً لاستخدامها في هذه الدراسـة، وهي: مهارات الاستماع: ويقصد بها في هذه الدراسة، مهارات الاستماع المحددة في أداة هذه الدراسة اللازم توافرها لدى الطلبة في المرحلة الأساسية

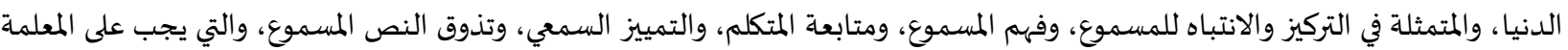
أن تمتلكها. امتلاك مهارات الاستماع: وتعني قدرة المعلمات وكفاءتهن، في معرفة وفهم هذه المهارات، وقد قيس بمجموع الدرجات التي حصلت عليها كل معلمة على الاختبار الذي طوره الباحثان لأغراض هذه الدراسة. المرحلة الأساسية الدنيا: هي المرحلة الأولى من مراحل التعليم العام وتشتمل على الصفوف من الأول وحتى السادس. 
2. الخلفية النظرية

تعد مهارة الاستماع من المهارات العقلية التي تشير إلى الاهتمام والعناية في استقبال المادة الصهوتية، بهدف الفهم والتحليل. وهي باكورة المهارات اللغوية التي تنمو وتتطور مع الإنسان منذ اللحظات الأولى من نشأته. إذ تزود هذه المهارة الإنسان بالمنطلق الذي سيبنى عليه تطوره اللغوي والفكري في

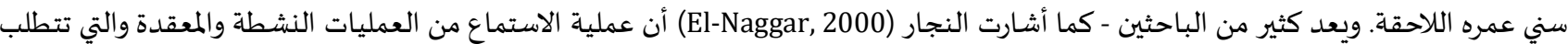
من المتعلم استقبال الأصوات وربطها مع بعضها البعض للوصول إلى المعنى وتخزين الرسالة لاستخدامها فيما بعد. ولأهمية هذه المهارة فإنه من الضروري القيام بتنظيم دورات تدريبية للمعلمين تخص الاستماع وأهميته، وأساليب تعليماه ومهاراته، وتوفير وسائل تعليمية مناسبة تساعد على تنمية هذه المهارة لدى الطلبة في مختبرات لغوية وشرائط وأجهزة تسجيل وقصص وهئ وغيرها (حلمي، 2005) إذ أن هذه الأدوات تسـاعد الطلبة على تعلم مهارة الاستماع وتبعث فيهم الرغبة وتسهل عملية التعلم.

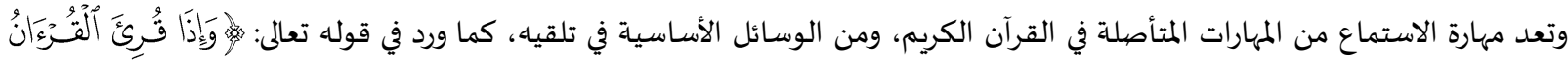

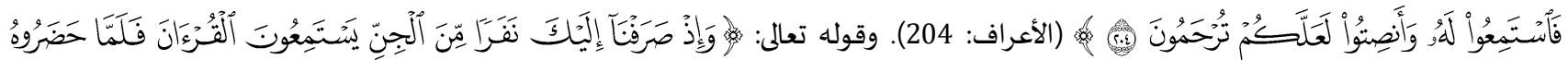

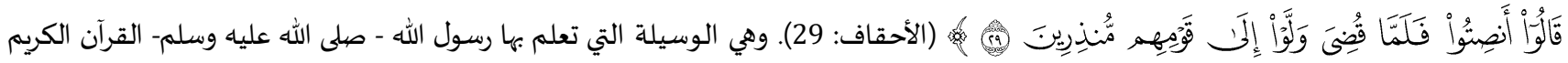
من جبريل-عليه السلام-، وعلم بها أصحابه -رضي الله عنهم-، ولقد كانت القاعدة المتبعة منذ عهد الرسول -صلى الله عليه وسلم- أن دارس القرآن الكريم يجب أن يتلقاه من أفواه المعلمين الضيابطين لألفاظه وأحكامه، وعدها المختصهون في مجال تعليم القرآن الكريم من الخطوات الأولى في تلقي

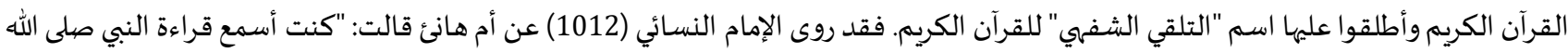
علياه وسلم وأنا على عريشي".

ومع كل هذه الأهميـة لهذه المهارة سـواء كان ذلك في تعلهم القرآن الكريم أو كمهارة لغوية عامـة، فقد أشـارت الدراسـات إلى أن هناك ضعفقًا عامًا عند المتعلمين وعند غيرهم في هذه المهارة، ويعود هذا الضعف إلى عدة أسباب، ومنها ما أشارت إليه دراسة الكشاش (2007) من أن:

الاعتقاد غير الصحيح لدى الكثيرين بأن مهارة الاستماع تنمو تدريجياً لدى الإنسان، دون الحاجة لتدريب الفرد على مهاراتها الفرعية المختلفة.

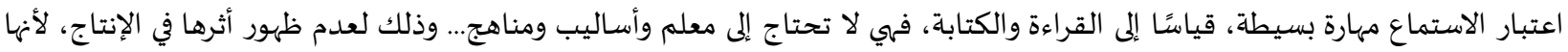
مهارة تلق، وما لا يظهر أثره، لا يعتد باه، ويهتم بتعليمها. التركيز في تعليم الطفل الكلام والنطق، وإهمال تعليماه الاستماع والإصغاء، وهو من السلوكيات اللغوية القديمة في المجتمع. وذلك ليبرع الطفل في عملية إنتاج الكلام، ويحصل كفاية التواصل مع الآخرين. ندرة الأبحاث التربوية التي تناولت الاستماع بصفته مهارة لغوية مستقلة، ودورها في اكتساب المهارات اللغوية الأخرى. أضف إلى ذلك بأن عدم الاهتمام بهذه المهارة بشكل مقصود في المنهج قد يؤدي إلى حدوث ظاهرتين لغويتين خطيرتين في مراحل التعليم العام، هما:

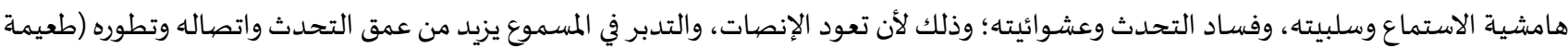
ومناع، 2001، 81) كما قد توصلت دراسة جانيوسيك (Janusik, 2002) إلى أن معظم المتعلمين لا يوجد لديهم مفهوم واضح للاستماع، أو الآلية التي يستطيعون من خلالها تحسين قدراتهم المرتبطة بهذه المهارة، لكي يصبحوا مستمعين جيدين وبشكل أكثر فاعلية. وهذا ما دفع الباحثين إلى التفكير في تشخيص الواقع الحالي، لامتلاك معلمات المرحلة الأساسية الدنيا لمهارات أساسية تساعدهم على تعليم الطلبة في مقرر التربية الإسلامية، وهي مهارة الاستماع، حيث أشار لافي (2014، 63) إلى أن حاسة السمع في مقدمة الحواس التي تسـاعد على التعلم، فهي مصدر كثير من المواقف التعليمية التي تساعد الطلبة على اكتساب المعلومات، والحصول على المعرفة، ومن خلالها يتم التفاعل والتواصل بينهم

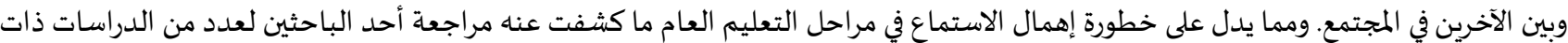

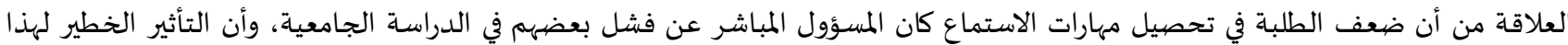
الضعف فاق التأثير ذاته الناتج عن الضعف في مهارات القراءة والكتابة (Canaway's, 1982). ولأهمية هذه المهارة أوصت دراسة (حلمي، 2005) بضرورة الإكثار من تدريب المعلمين على مهارات الاستماع، وألّا يقتصر هذا التدريب على مدرسي

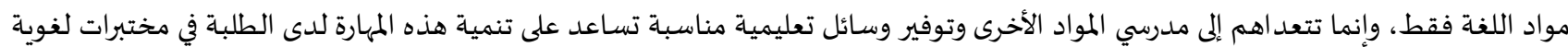
وشرائط وأجهزة تسجيل وقصص وغيرها، إذ أن هذه الأمور تساعد الطلبة على تعلم مهارات الاستماع وتبعث فيهم الرغبة وتسهل عملية التعلم.

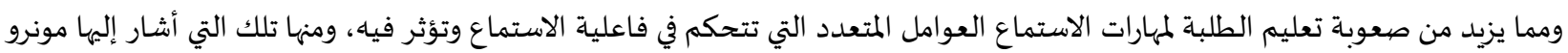
(1978، 112) كطبيعة الموضوع الذي نستمع إليه، وطريقة عرض الموضوع، وبيئة الاستماع، وحال المتلقي نفسه. ولذا فقد يكون من الصعب تحديد 
العامل أو العوامل المسؤولة مباشرة عن هذه المهارة. وبالتالي فإنه يلزم لتدريس مهارات الاستماع وجود معلم جيد قدوة يمتلك مهارات الاستماع ولدياه

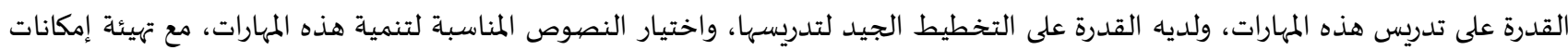
الاستماع الجيد (البدري، 1990).

1.2. - n الدراسـات السابقة

لقد تنوعت نتائج الدراسات التي قامت بتقصي امتلاك معلمي التربية الإسلامية عامة، ومعلمات المرحلة الأساسية الدنيا لمهارات التدريس المختلفة، فقد توصلت بعض هذه الدراسات إلى أن المعلمين يمتلكون هذه المهارات بدرجة مرتفعة. كدراسة آل محفوظ (2020) التي هدفت إلى تعرف درجة امتلاك معلمي التربية الإسلامية بالمرحلة الابتدائية للكفايات التدريسية اللازمة من

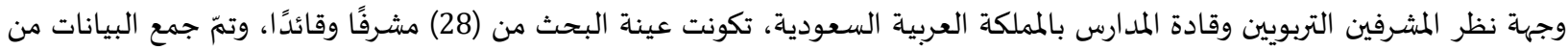

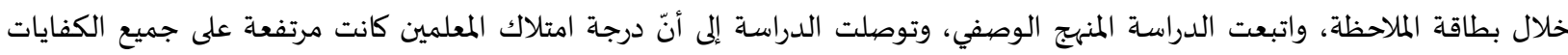

وأظهرت دراسة دهيم (2019) التي هدفت إلى تعرف مدى امتلاك معلمات اللغة العربية في المرحلة الابتدائية في الكويت للكفايات التدريسية، وأثر متغيري الخبرة والمنطقة التعليمية في ذلك. واتبعت الدراسة المنهج الوصفي التحليلي، وتكونت عينة الدراسة من (137) معلمة من معلمات

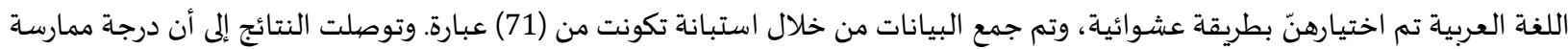

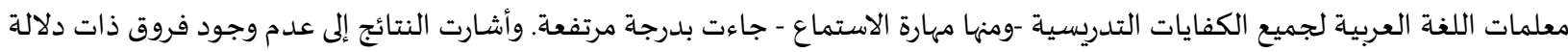
إحصائية حول مدى امتلاك معلمات اللغة العربية للكفايات التدريسية تعزى لمتغيري الخبرة والمنطقة التعليمية. ودراسـة الرقيبات (2018) التي هدفت إلى الكشف عن درجة امتلاك معلمي التربية الإسلامية للكفايات المهنية في تدريس التربية الإسلامية للطلبة من وجهة نظر مديري المدارس في محافظة المفرق، وتكونت عينة الدراسة من (325) مديرًا ومديرة، وأشارت نتائج هذه الدراسـة إلى أن درجة

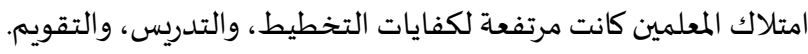
ودراسـة العكيلي، والقرالة (2017) التي هدفت إلى التعرف إلى درجة امتلاك معلمي التربية الإسلامية لمهارات الأسئلة الصفية للمرحلة الأساسية

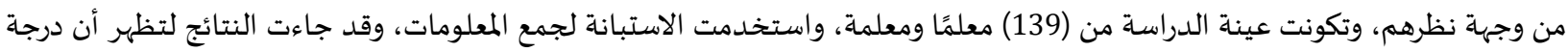
امتلاك المعلمين لهذه المهارات كانت بدرجة مرتفعة، وأن هناك فروق دالة إحصائيًا تعزى لمتغير المؤهل العلمي ولصالح الدراسات العليا، ولمتغير الخبرة ولصالح ذوي الخبرات الطويلة. ودراسـة الزبون (2014) التي هدفت إلى معرفة درجة امتلاك معلمي التربية الإسلامية في المرحلة الثانوية لكفايات التدريس بدولة الإمارات العبربية

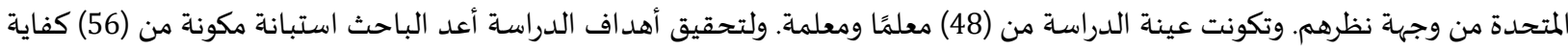

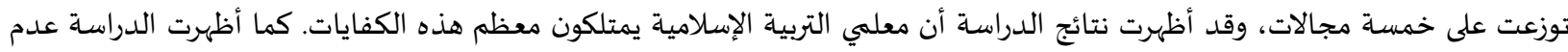
وجود فروق دالة إحصائياً في درجة امتلاك معلمي التربية الإسلامية لكفايات التدريس تعزى لمتغير الجنس أو الخبرة في كل مجال من مجالات الأداة الخمسة، وعلى مستوى الأداة ككل. ودراسة الخالدي (2013) التي هدفت إلى الكشف عن درجة امتلاك معلمي التربية الإسلامية ومعلماتها، في وزارة التربية والتعليم في الأردن، لمفاهيم الاقتصياد المعرفي في ضوء بعض المتغيرات الديمغرافية، ولتحقيق ذلك صهمم الباحث استبانة تكونت من (35) فقرة، وتم تطبيقها على

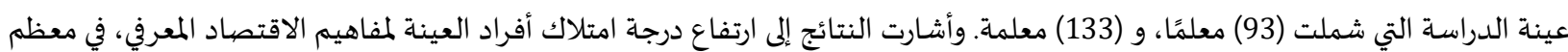

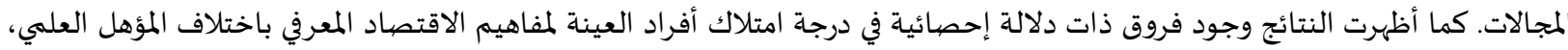

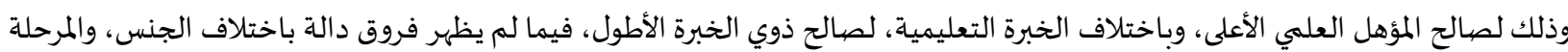
التعليمية. ودراسـة خزعل ومومني (2010) التي سعت إلى معرفة درجة امتلاك معلمات المرحلة الأساسية الدنيا في المدارس الخاصة التابعة لوزارة التربية

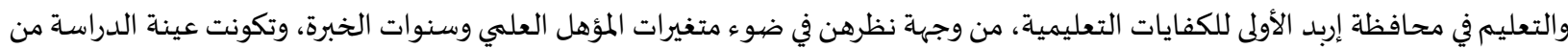
(168) معلمة. استخدم الباحثان استبانة مكونة من (38) كفاية، وقد أظهرت نتائج الدراسـة أن أبرز الكفايات التي تمتلكها المعلمات هي: استغلال

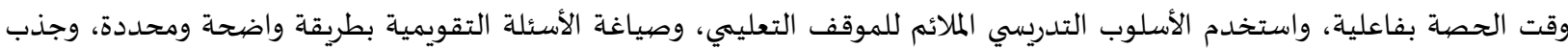
انتباه الطلبة، والمحافظة على استمراريته، كما بينت نتائج الدراسة عدم وجود فروق ذات دلالة إحصائية تعزى لمتغير الخبرة التعليمية. 
في حين أن هناك دراسات أخرى قد أشارت إلى أن امتلاك المعلمين لبعض المهارات اللازمة لهم في عملية التعليم كانت متوسطة وبحاجة إلى بعض التحسين والصقل:

كدراسة الشمري (2018) التي هدفت إلى تعرف درجة امتلاك وممارسة معلمي الصفوف الأولى لاستراتيجيات التقويم البديل في المدارس

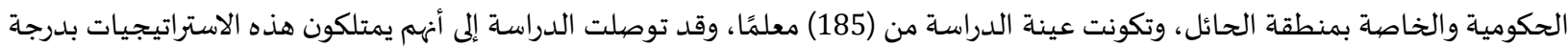

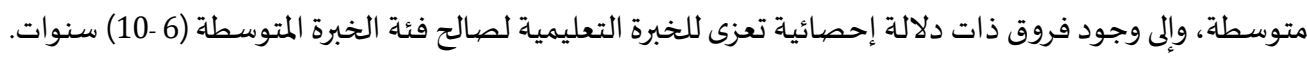
ودراسة اليوسف (2017) التي هدفت إلى الكشف عن درجة امتلاك معلمي التربية الإِلامية في محافظة العاصمة عمان لكفايات استخدام

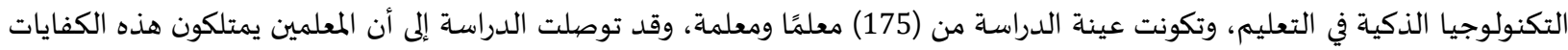

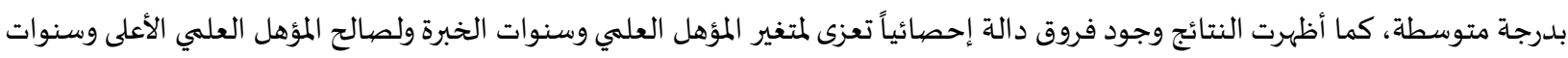
الخبرة الأعلى. ودراسـة البداح (2006) التي هدفت إلى معرفة درجة توافر الكفايات التعليمية لدى معلمي التربية الإسلامية في الحلقة الثانية بالمملكة العربية

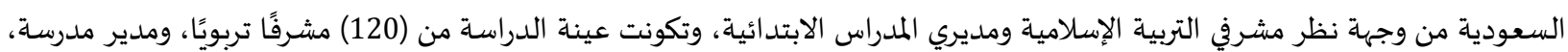

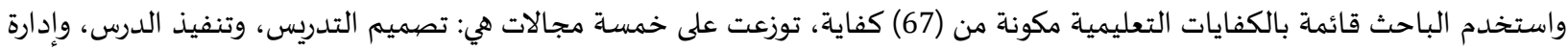

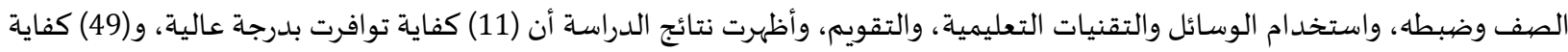
توافرت بدرجة متوسطة، و (7) كفايات توافرت بدرجة متدنية.

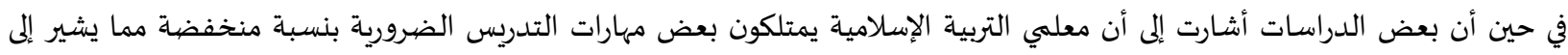
ضعفهم فيها: • كدراسة القرشي (2018) التي هدفت إلى معرفة مستوى تمكن معلمات اللغة العربية من أساليب تنمية مهارات الاستماع الناقد لتلميذات

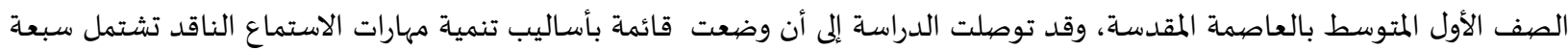

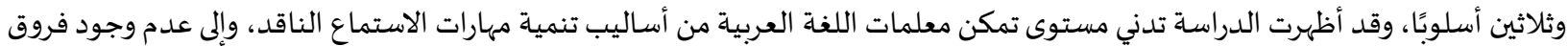

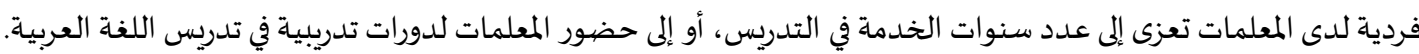
لقد تشابهت الدراسة الحالية مع الدراسات السابقة في منهجية البحث والمعتمدة على المنهجية الوصفية، في حين أن هذه الدراسة هي الدراسة

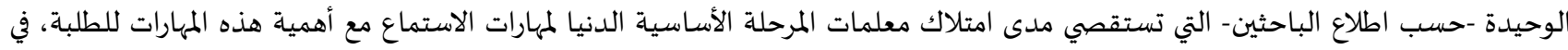
الوقت الذي ركزت فياه الدراسـات السابقة على الكفايات العامة في التدريس أو كفايات خاصة أخرى. وأيضاً تميزت هذه الدراسـة باستخدام أداة

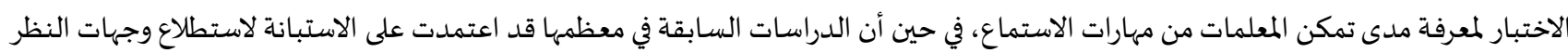
حول امتلاك هذه المهارات أو قائمة الرصديد والملاحظة.

2.2. مجتمع الدراسة وعينتها: يمثل مجتمع الدراسـة جميع معلمات المرحلة الأسـاسية الدنيا في مديرية التربية والتعليم للواء قصبية عمان التابعة لوزارة التربية والتعليم للعام الدراسي (2021/2020). والبالغ عددهن (1723) معلماة، وذلك وفقًا للسجلات الرسمية لمديرية التربية والتعليم، وقام الباحثان باختيار هذه المديرية لقربها من مكان عملهما. وقد أجريت الدراسة على عينة قوامها (307) معلمة - حيث إن هذه الصفوف لا يقوم بتدريسها إلا معلمات وفق قانون وزارة التربية والتعليم الأردنية، وقد تم اختيارهن بطريقة المعاينة العرضية Accidental Sampling وهي تشير إلى استخدام الحالات المتيسرة للدراسة بالنسبة النسبة للباحثين، وبنسبة تمثيل (20\%) تقريبًا، والجدول (1) يشير إلى توزيع عينة الدراسة حسب المؤهل العلمي وحسب مؤهل الخبرات التعليمية - والتي تم قياسها بعدد سنوات الخدمة في التعليم.

جدول (1): توزيع أفراد العينة حسب المؤهل العلمي وسنوات الخبرة

\begin{tabular}{|c|c|c|c|c|}
\hline \multicolumn{4}{|c|}{ سنوات الخبرة } & \multirow[t]{2}{*}{ المؤهل العلمي } \\
\hline المجموع الكلي & أكثر من 10 & $10-5$ & أقل من 5 & \\
\hline 105 & 37 & 35 & 33 & الدبلوم \\
\hline 107 & 35 & 35 & 37 & البكالوريوس \\
\hline 95 & 29 & 33 & 33 & الدراسات العليا \\
\hline 307 & 101 & 103 & 103 & المجموع الكلي \\
\hline
\end{tabular}


3.2.

اتبع الباحثان المنهج الوصفي لتنفيذ هذه الدراسة، كونها يعتمد على دراسة الظاهرة كما توجد في الواقع، ويهتم بوصفها وصفًا دقيقًا، ويعبر عنها

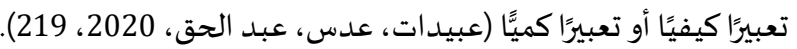

4.2. أداة الدراسةة:

لتحقيق أهدف هذه الدراسة، والإجابة عن أسئلتها تألفت أداة الدراسة من قسمين:

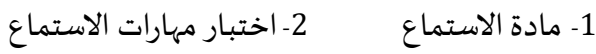

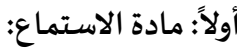

ولأغراض قياس مهارة الاستماع من خلال بناء الاختبار قام الباحثان بالإجراءات الآتياة:

تحديد موضوع الاختبار -المحتوى السمعي- وتمثل ذلك في تحديد جزء من سورة الأحزاب من آية (28 - 40) التي تتحدث عن علاقة الرسول -صلى

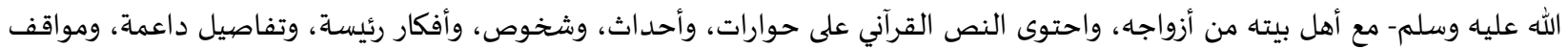
تستدعي النقد، وعمل استنتاجات محتملة.

التأكد من عدم حفظ المعلمات لهذه الآيات القرآنية، وتم التأكد من ذلك من خلال اختبار المعلمات في حفظها، وكان هناك معلمتان يحفظن السورة وتمّ استبعادهن من الاختبار. تحليل محتويات النص إلى عناصر صنفت في قوائم تحت عناوين: الشخوص، الأحداث المتسلسلة، الأفكار الرئيسة، التفاصيل الدائمة، الكلمات

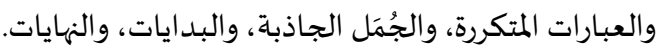

تم اعتماد نسخة واضحة مسجلة لصوت مقرئين مختلفين (الشيخ محمود الحصري، والشيخ محمد المنشاوي) لهذه السورة، وتم مراعاة أن تكون قراءتهما مجودة حيث يضمن أن تكون سرعة القراءة ليست سريعة ولا بطيئة. تم تحديد زمن تلاوة كل مقرئ؛ حيث كانت من (6-8) دقائق وهو زمن مقبول لعمل الاختبار لمهارة الاستماع.

ثانيًا: اختبار الاستماع:

وقد تمّ بناء الاختبار وفق الخطوات الآتية:

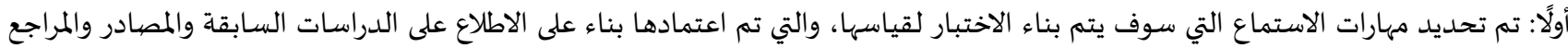

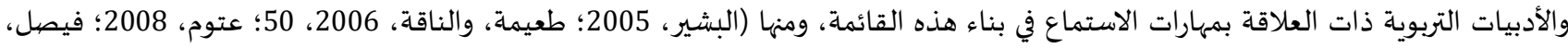

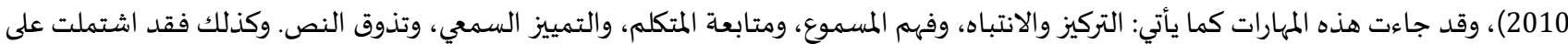
(30) مهارة فرعياة. وذلك على النحو الآتي:

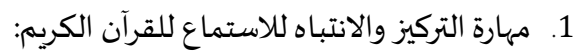
أ) ت تذكر بداية الآيات.

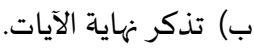
ج) تذكر بعض المعلومات المتضمنة في الآيات. د) تعرف العبارة/ الكلمة المتكررة في الآيات.

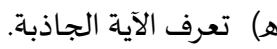

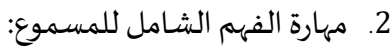
أ) تفسير الكلمات والمعاني ويشتمل على: ب) تحديد الفكرة الرئيسة في الآيات المسموعة،، ويشتمل على: ج) القدرة على تصنيف الأفكار التي تعرض لها القارئ. د) تحديد عناصر الآيات (الشخصيات والأحد اث والأزمنة والأماكن). هـ التفريق بين ما له علاقة بموضيوع الآيات المسموعة وما ليس لله علاقة بالموضوع. و) إدراك تأثير التنغيم في معنى الآيات. 3. مهارة متابعة القارئ: أ) تعرف الآيات السابقة. 


$$
\begin{aligned}
& \text { ب) تعرف الآيات اللاحقة. }
\end{aligned}
$$

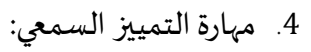

$$
\begin{aligned}
& \text { أ) تمييز الكلمات والعبارات في الآيات التي تحمل مشاعر مختلفة (مثل، الحزن، والسعادة، والتهنئة). } \\
& \text { ب) تمييز الكلمات في الفاصلة القرآنية. } \\
& \text { ج) تحديد الكلمة التي تنتهي بصوت مختلف عن باقي الكلمات في الآية/ الآيات. } \\
& \text { د) تمييز الكلمتين المتشابهتين في عدد من الحروف الصهوتية في الآية/ الآيات. } \\
& \text { هـ) تعرف مواضيع الخطأ القرائي للقارئ. } \\
& \text { و) تمييز الرموز الصوتية المتقاربة في النطق والشكل. }
\end{aligned}
$$

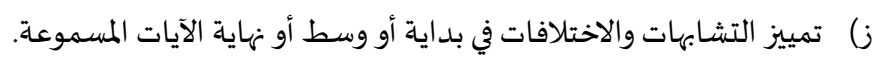

$$
\begin{aligned}
& \text { ح) تمييز أحكام التلاوة والتجويد. } \\
& \text { ط) تمييز أصوات المقرئين. } \\
& \text { 5. مهارة تذوق النص القرآني: } \\
& \text { أ) إظهار الإعجاب أو الاستياء من بعض الشخرفي الشخيات أو المواقف في الآيات التي استمع إليها. } \\
& \text { ب) إدراك نوع الانفعال عند الاستماع للآيات القرآنية. } \\
& \text { ج) تحديد مواطن الإعجاب فيما يستمع إليه، سواء في الألفاظ، أو العبارات، أو التركيب الكلي. } \\
& \text { د) التمييز بين كلام المتكلمين في الآية/ الآيات. } \\
& \text { هـ التعليق على ما يستمع إليه تعليقاً مناسباً. } \\
& \text { و) المقارنة بين العبارات التي تحمل معاني متعارضية. } \\
& \text { ز) المقارنة بين العبارات التي تحمل معاني متقاربة. }
\end{aligned}
$$

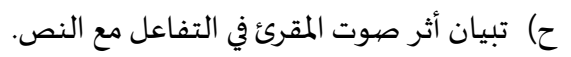

ثانيًا، تم بناء الاختبار في صورته الأولية من (70) فقرة من نوع الاختيار من متعدد، وضعت التهاء لتغطي في مجملها المؤشرات السلوكية ذات العلاقة بمهارات

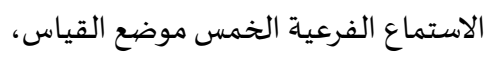

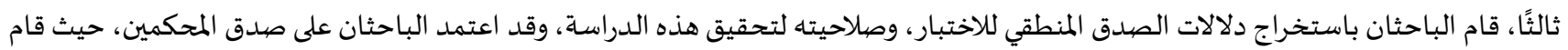

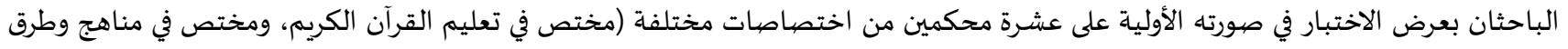

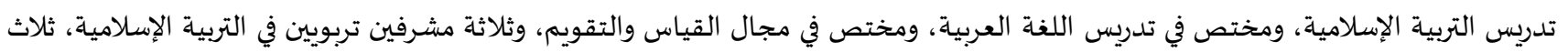

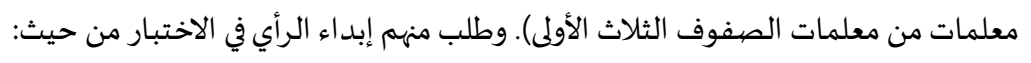

$$
\begin{aligned}
& \text { • مدى مناسبة المهارة للمعلمات. } \\
& \text { مدى ارتباط المهارات الفرعية بالمهارة الرئيسة. } \\
& \text { صححة المحتوى العلمي للمهارة. } \\
& \text { سلامة الصياغة اللغوية للمهارة. } \\
& \text { • نقل بعض المهارات من مستوى إلى مستوى آخر. } \\
& \text { • حذف، أو تعديل، أو إضافة مهارات أخرى. } \\
& \text { دقة تعليمات الاختبار. }
\end{aligned}
$$

وقد تم استبقاء الفقرات التي اتفق 80\% من المحكمين على صلاحيتها، كما تم تعديل بعض الفيار الفقرات، وحذفت الفقرات غير المناسبة في ضوء

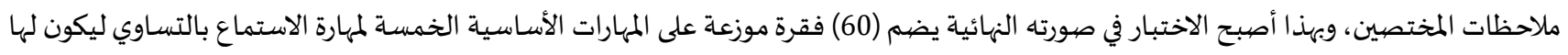

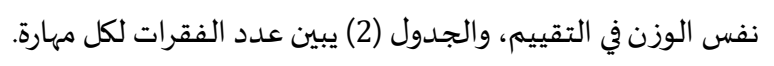




\begin{tabular}{|c|c|}
\hline عدد الفقرات & مهارات الاستماع \\
\hline 12 & التركيز والانتباه \\
\hline 12 & فهم المسموع \\
\hline 12 & متابعة المتكلم \\
\hline 12 & التمييز السمعي \\
\hline 12 & تذوق النص \\
\hline 60 & المجموع الكلي \\
\hline
\end{tabular}

رابعًا، تطبيق الاختبار على عينة الثبات التي بلغت 60 معلمة، وهنّ من مجتمع الدراسة ومن خارج عينتها. وذلك من أجل ما يأتي:

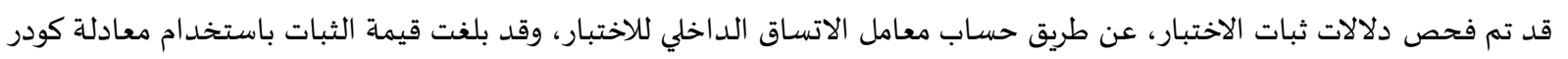

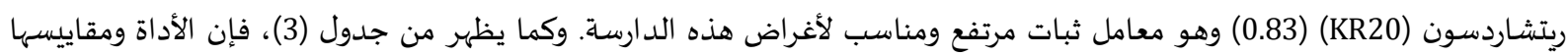
الفرعية تتمتع بدرجة عالية ومقبولة من الثبات الداخلي.

\begin{tabular}{|c|c|c|}
\hline معامل الاتساق الداخلي & معامل الاستقرار & مهارات الاستماع \\
\hline 0.84 & 0.88 & التركيز والانتباه \\
\hline 0.87 & 0.87 & فهم المسسموع \\
\hline 0.80 & 0.83 & متابعة المتكلم \\
\hline 0.89 & 0.91 & التمييز السمعي \\
\hline 0.85 & 0.88 & تذوق النص \\
\hline 0.83 & 0.87 & المجموع الكلي \\
\hline
\end{tabular}

تم استخراج معامل الصعوبة للفقرات بناء على نتيجة عينة الثبات السالفة، وقد تراوحت ما بين (0.33 - 0.65) وهي نسبة مقبولة. وأما

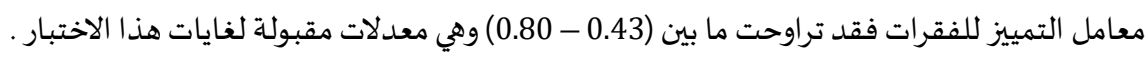

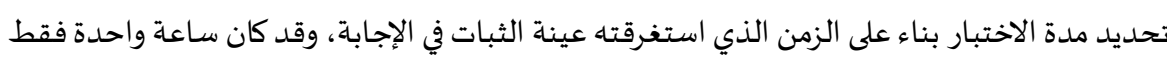

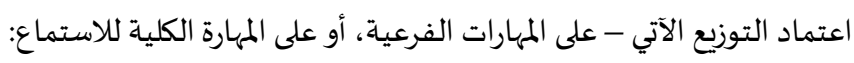
- - النسبة المئوية للمتوسط الحسابي من (59\% - 0\%) يشير إلى درجة امتلاك منخفضية.

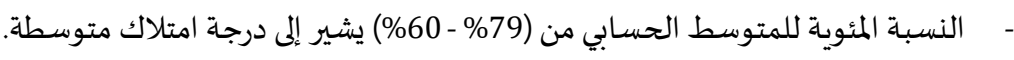
- - النسبة المئوية للمتوسط الحسابي من (100\% - 80\%) يشير إلى درجة امتلاك مرتفعة.

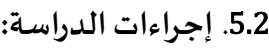

للإجابة عن تساؤلات الدراسة قام الباحثان بالإجراءات الآتية:

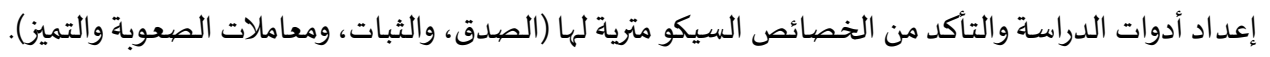
اختيار عينة الدراسة.

• أخذ الموافقة من وزارة التربية والتعليم الأردنية على تطبيق الأدوات على المعلمات من مديرية التربية والتعليم المعنية.

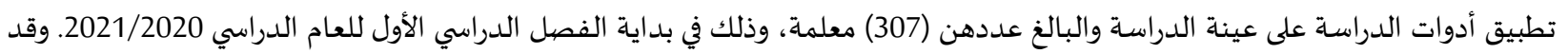
كان ذلك على شكل مجموعات مختلفة الأعداد، وبفترات مختلفة بسبب الظروف التي تمر بها المدراس بسبب جائحة مرض الكورئ الكورنا.

$$
\text { تقديم التوصيات والمقترحات في ضوء نتائج الدراسة. }
$$

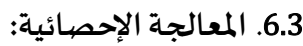

للإجابة عن السؤال الأول من الدراسة، تم حساب المتوسطات الحسابية، والانحرافات المعيارية لدرجات أفراد الدراسة على اختبار مهارات

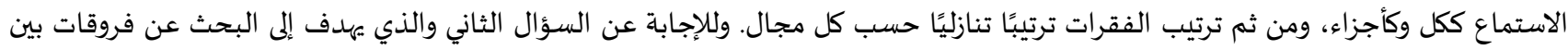

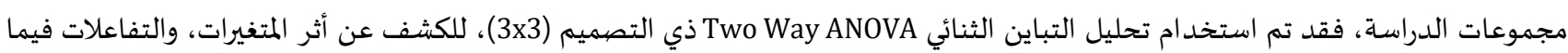


بينها، وذلك بعد التأكد من شروط تحقق هذا التحليل، هذا بالإضافة إلى اختبار شيفيه للمقارنات المتعددة للكشف عن طبيعة التباين ومصدره بين مجموعات الدراسـة.

\section{3. عرض النتائج والمناقشة}

1.3. عرض نتائج السؤال الأول: والذي ينص على: ما درجة امتلاك معلمات المرحلة الأساسية الدنيا لمهارات الاستماع للقرآن الكربم؟ الماتئ

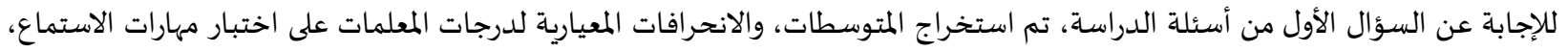

ويبين الجدول (4) قيم هذه المتوسطات، والانحرافات المعيارية.

جدول (4): المتوسطات الحسابية والانحر افات المعيارية لفقرات الاختباروفق كل مهارة من مهارات الاستماع

\begin{tabular}{|c|c|c|c|c|}
\hline الرتبة & المستوى & الإنحراف المعياري & نسبة التحقق & لمهارة المهار \\
\hline 5 & منخفض & 2.93 & 0.50 & التركيز والانتباه \\
\hline 2 & متوسط & 16.41 & 0.61 & فهم المسموع \\
\hline 4 & منخفض & 10.48 & 0.54 & متابعة المتكلم \\
\hline 3 & منخفض & 10.72 & 0.55 & التمييز السمعي \\
\hline \multirow[t]{2}{*}{1} & متوسط & 16.80 & 0.64 & تذوق النص \\
\hline & منخفض & 6.80 & 0.57 & المجمموع الكلي \\
\hline
\end{tabular}

والشكل (1) التالي يوضيح مدى امتلاك المعلمات لمهارات الاستماع الفرعية.

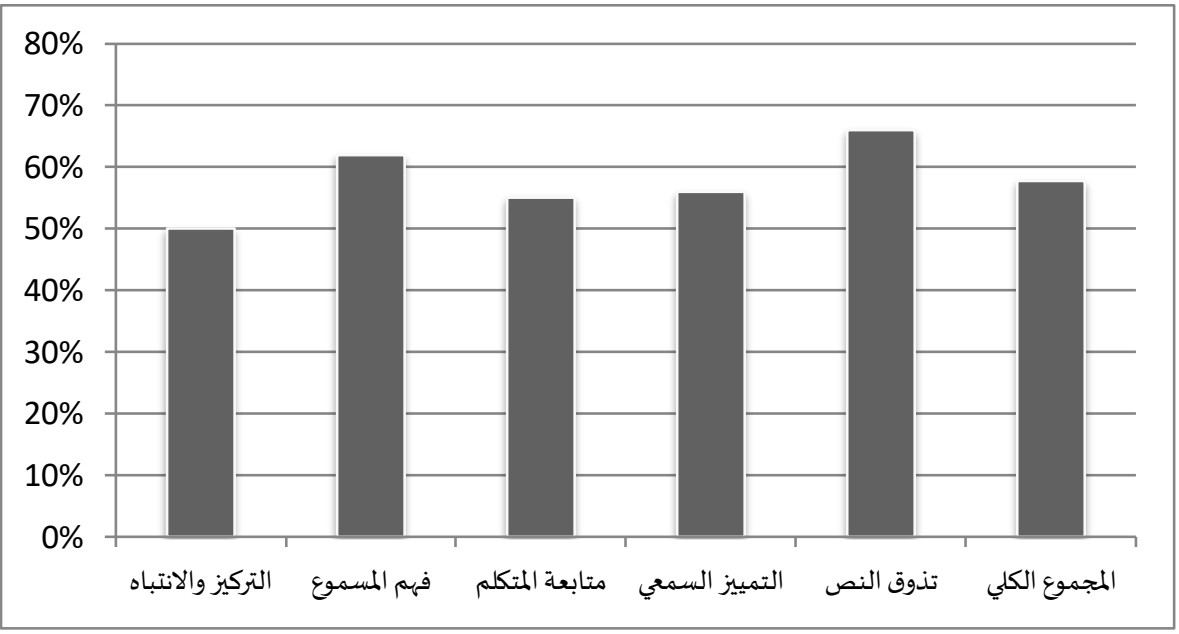

شكل (1): مدى امتلاك معلمات المرحلة الأساسية الدنيا لمهارات الاستماع الفرعية

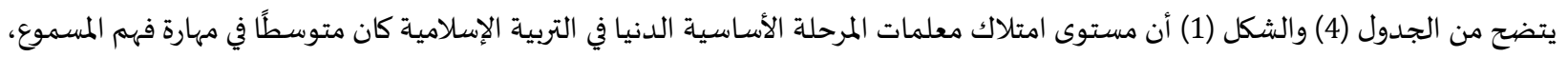

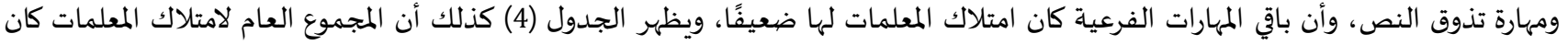

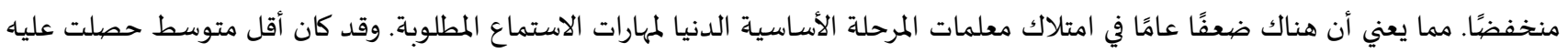

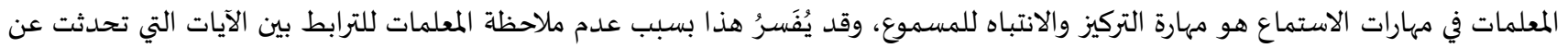

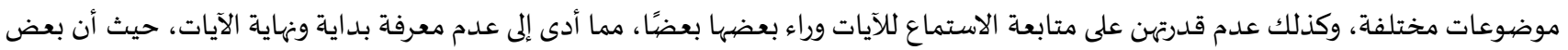

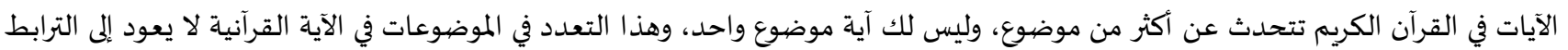

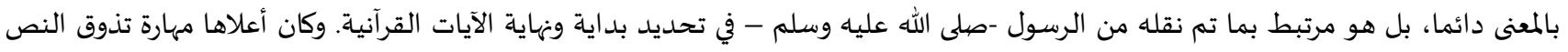

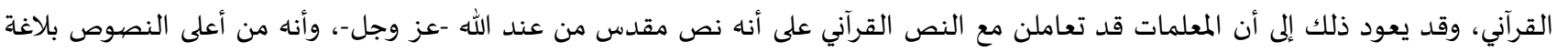

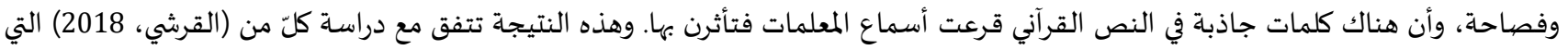

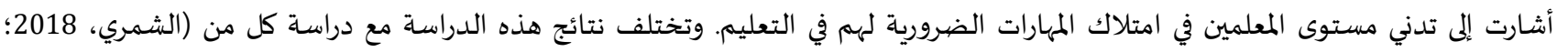

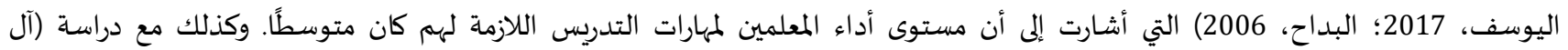

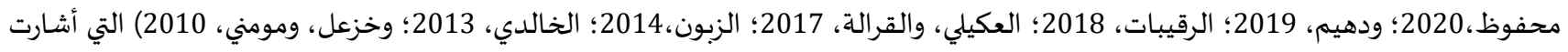


إلى امتلاك المعلمين كان للمهارات المطلوبة منهم مرتفعًا، وقد يعود ذلك الاختلاف إلى أن هذه الدراسة تقيس مدى امتلاك المعلمات إلى مهارات متخصصية - مهارات الاستماع - وليس لمهارات والكفايات التدريسية بشكل عام.

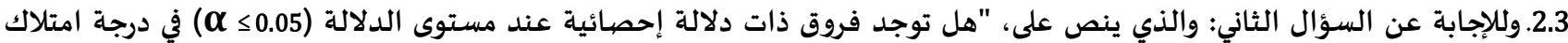
معلمات المرحلة الأسـاسية الدنيا لمهارات الاستماع للقرآن الكريم، تعزى لمتغيرات الخبرة التعليمية، أو المؤهل العلمي، أو التفاعل بينهما؟" إنها؟

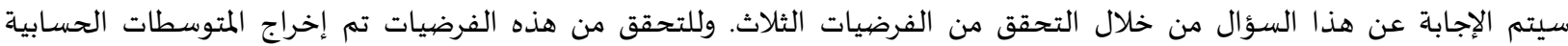
والانحرافات المعيارية على اختبار مهارات الاستماع للمعلمات، كما هو مبين في الجدول (5): جدول (5): المتوسطات الحسابية والانحر افات المعياربة على اختبار مهارات الاستماع للمعلمات

\begin{tabular}{|c|c|c|c|c|}
\hline العدد العد & الانحراف المعياري & المتوسط & المؤهل العلمي & الخبرة \\
\hline 33 & 5.63 & 54.88 & دبلوم & أقل من 5 سنوات \\
\hline 37 & 5.31 & 55.52 & بكالوريوس & \\
\hline 33 & 4.76 & 54.99 & دراسات عليا & \\
\hline 35 & 7.31 & 58.79 & دبلوم & 6 - 6 سنوات \\
\hline 35 & 6.94 & 57.98 & بكالوريوس & \\
\hline 33 & 7.47 & 58.48 & دراسات عليا & \\
\hline 37 & 7.25 & 58.13 & دبلوم & أكثر من 11 سنة \\
\hline 35 & 7.71 & 57.89 & بكالوريوس & \\
\hline 29 & 7.50 & 57.25 & دراسات عليا & \\
\hline
\end{tabular}

يبين الجدول (5) أن المتوسطات الحسابية للمجموعات مختلفة، وأن متوسط المعلمات ذوات الخبرة من 6 -10 سنوات ممن يحملن درجة الدبلوم كان أعلى متوسط في المجموعات، وأن أدنى متوسط في المجموعات كان للمعلمات ذوات الخبرة أحبرة أقل من 5 سنوات ممن يحملن درجة الدبلوم.

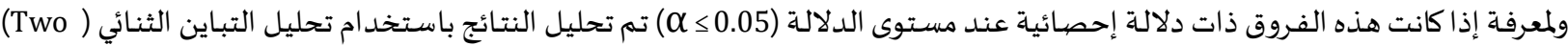
Way ANOVA وقد قام الباحثان بالتحقق من توافر الشروط اللازمة لاستخدام هذا الاختبار من حيث اعتدالية العينة بالتوزيع الطبيعي، واستقلالية

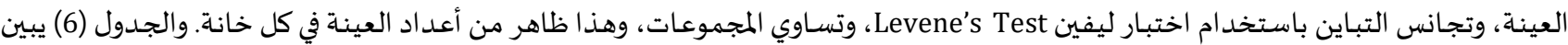
نتائج تحليل التباين الثنائي لدرجات المعلمات:

\begin{tabular}{|c|c|c|c|c|c|c|}
\hline مستوى الدلالة العملية إيتاً (Eta²) & الدسلالة & قيمة “ف" & المتوسطات & الحربة & مجموع المربعات & مصدر التباين \\
\hline 0.04 & *.001 & 6.83 & $\begin{array}{c}309.1 \\
3\end{array}$ & 2 & 618.26 & الخبرة التعليمية \\
\hline 0.00 & .930 & .07 & 3.27 & 2 & 6.54 & المؤهل العلمي \\
\hline \multirow[t]{3}{*}{0.00} & .964 & .15 & 6.63 & 4 & 26.54 & الخبرة * المؤهل العلهي \\
\hline & & & 45.26 & 298 & 13488.14 & الخطأ \\
\hline & & & & 307 & 1015553.96 & المجموع \\
\hline
\end{tabular}

من خلال الجدول (6) يتبين: رفض الفرضية الأولى التي تنص على أنه ((لا توجد فروق ذات دلالة إحصائية عند مستوى الدلالة (0.05 ه) في درجة امتلاك معلمات المرحلة

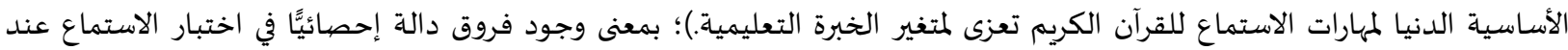
مستوى الدلالة (0.05 $\alpha$ ئ يعزى للخبرة التعليمية (أقل من 5 سنوات، من 6-10 سنوات، أكثر من 11 سنة)، وهذه النتيجة مخالفة للنتيجة التي توصلت لها دراسة (القرشي، 2018؛ الزبون، 2014؛ خزعل، ومومني، 2010) والتي أشارت لعدم وجود فروق بين المعلمات تعزى لمتغيرات الخبرة التعليمية في امتلاك مهارات الاستماع. وهذا بخلاف الدراسات التي اتفقت مع ما توصلت إليه هذه الدراسة، من مثل مندي (دهيم، 2019؛ الشمري، 2018؛ اليوسف، 2017؛ القرالة، 2017؛ الخالدي، 2013) التي أشارت إلى وجود فروق دالة إحصائيًا لمتغير الخبرة التعليمية في امتلاك مه مهاك مهارات الاستماع. وقد يرجع ذلك إلى طول الخبرة بين المعلمات والتي يمكن أن تكون المعلمات خلالها قد اطلعن عن معلومات أو مهارات ذات ذات

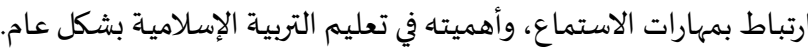

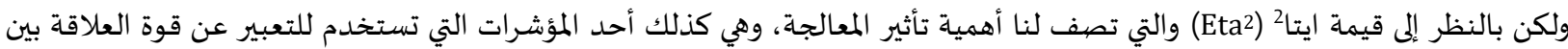
المتغيرات، فقد بلغت (0.04) وهي قيمة منخفضية. مما يعنى أنه مع وجود فروق ذات دلالة إحصائية هنا إلى أهها ذات دلالة عملية منخفضية. 


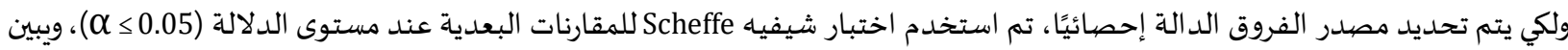
الجدول (7) الدلالات الإحصائية للفروق بين متوسطات المجموعات الثلاثة للمعلمات على متغير الخبرة التعليمياة.

\begin{tabular}{|c|c|c|c|}
\hline أكثر من 11 سنة & من 6 - 10 سنوات & أقل من 5 سنوات & الخبرة \\
\hline$-2.64 *$ & $-3.27 *$ & & أقل من 5 سنوات \\
\hline \multirow[t]{2}{*}{0.62} & & $3.27 *$ & من 6 - 10 سنوات \\
\hline & -0.62 & $2.64 *$ & أكثر من 11 سنة \\
\hline
\end{tabular}

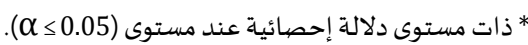

$$
\text { ويظهر من الجدول (7) أن: }
$$

وجود فروق دالة إحصائيًا بين المعلمات ذوات الخبرة أقل من 5 سنوات، والمعلمات ذوات الخبرة من 6 -10سنوات، وذوات الخبرة أقل من 5

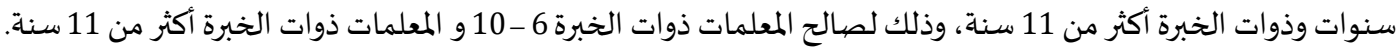
عدم وجود فروق د الة إحصائيًا بين المعلمات ذوات الخبرة 6-10 سنوات والمعلمات ذوات الخبرة أكثر من 11 سنة. وهذا يشير إلى أن امتلاك المهارات يتأثر بطول الفترة الزمنية بدرجة محدودة في البداية، وهذا ما أكدته قيمة ايتا2 (Eta2) فقد بلغت (0.04) وهي

قبول الفرضية الثانية التي تنص على أنه، "لا توجد فروق ذات دلالة إحصائية عند مستوى الدلالة (0.05 ه) في درجة امتلاك معلمات المرحلة الأساسية الدنيا لمهارات الاستماع للقرآن الكريم تعزى لمتغير المؤهل العلمي"؛ بمعنى عدم وجود فروق دالة إحصيائيا في اختبار الاستماع عند

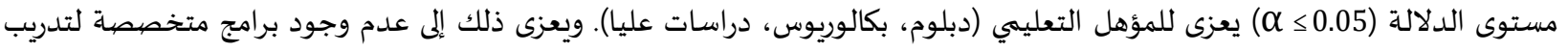

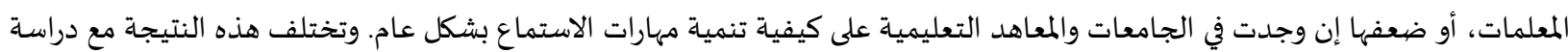
(العكيلي، والقرالة، 2017؛ اليوسف، 2017؛ الخالدي، 2013) التي أشارت إلى وجود فروق دالة إحصائياً لمتغير المؤهل العلمي على امتلاك المعلمين للمهارات الضرورية لهم في التعليم وذلك لصالح الدراسات العليا. قبول الفرضية الثالثة التي تنص على أنه، " لا توجد فروق ذات دلالة إحصائية عند مستوى الدلالة (0.05 ه) في درجة امتلاك معلمات المرحلة الأساسية الدنيا لمهارات الاستماع للقرآن الكريم تعزى للتفاعل بين متغيري الخبرة والمؤهل العلمي"؛ بمعنى عدم وجود فروق دالة إحصائيا في

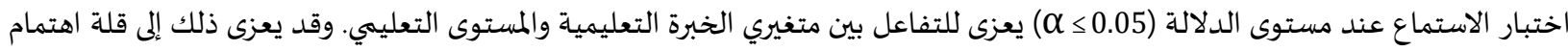
الجامعات ومراكز تدريب المعلمين في تمليك المعلمين لمهارات الاستماع الخاصة بكل موضوع دراسي، حيث إن النتيجة تشير إلى عدم امتلكهم لها في

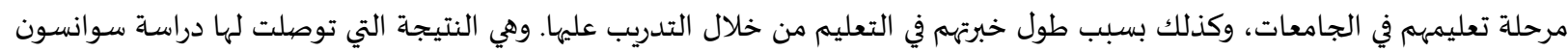
(Swanson, 1986)

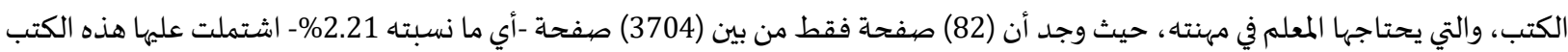

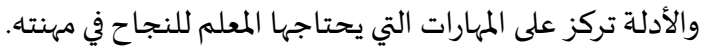

الخلاصية:

توصلت الدراسـة إلى النتائج الآتياة:

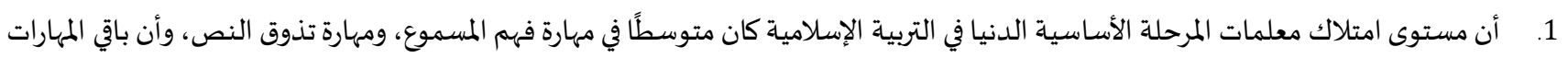

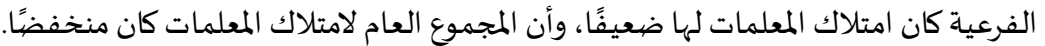

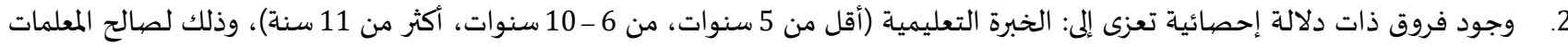

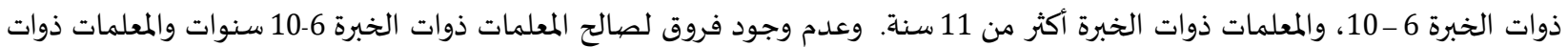
الخبرة أكثر من 11 سنة. وأن قيمة ايتا (Eta²) فقد بلغت (0.04) وهي قيمة منخفضة. مما يعنى أنه مع وجود فروق ذات ذات دلالة إحصائية هنا إلى أنها ذات دلالة عملية منخفضية. 3. عدم وجود فروق ذات دلالة إحصيائية تعزى إلى: المؤهل التعليمي (دبلوم، بكالوريوس، دراسات عليا). التفاعل بين متغيري الخبرة التعليمية والمستوى التعليمي. 
في ضوء ما توصل إليه الباحثان من نتائج يمكن تقديم التوصيات الآتياة:

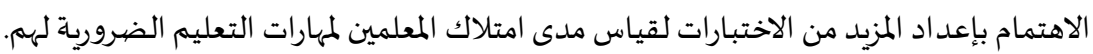
تضيمين برامج إعداد معلمي التربية الإسلامية واللغة العربية في الجامعات والمعاهد، مهارات الاستماع للقرآن الكريم، وأساليب تنميته لدى الطلبة. ضرورة عقد دورات تدربيية لمعلمي التربية الإسلامية واللغة العربية أثناء الخدمة لتدربههم على أساليب تنمية مهارات الاستماع في شتى المراحل

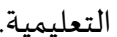

الاهتمام بمهارات الاستماع عند تأليف كتب التربية الإِلامية واللغة العربية للمرحلة الأساسية بما يناسب هذه المرحلة العمرية. تنمية اتجاهات معلمي التربية الإسلامية واللغة العربية نحو تعلم مهارات الاستماع من خلال التوعية والتدريب. إعادة الدراسة على عينات مختلفة من الطلبة. إجراء مزيد من الدراسات حول تنمية مهارة الاستماع لتعلم القرآن الكريم. الاستعانة بمهارات الاستماع التي تم الحديث عنها في هذه الدراسة في تسهيل عمل المدربين وكليات التربية لتدريب المعلمين، والمشرفين التربويين.

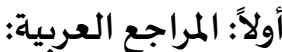

1. البداح، فهد (2006). ملدى توفر الكفايات التعليمية لدى معلمي التوبية الإسلامية في الحلقة الثانية من المرحلة الابتدائية بالمملكة العربية

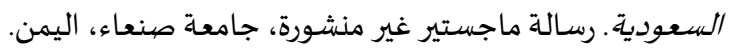
2. البدري، المهدي (1990). مهارات الاستماع لدى طلاب در المعلمين والمعلمات، دراسة تقويمية. رسالة دكتوراه غير منشورة، كلية التربية، جامعاة المنصورة. 3. البشير، أكرم (2005). مهارة الاستماع في منهاج اللغة العببية لصفوف الحلقة الثانية من الممحلة الأساسية في الأردن: دراسة تحليلية. المجلة التربوية: 20 (77): 99 - 127.

4. الجلاد، ماجد (2007). تلدريس التوبية الإسِالامية: الأسس النظرية والأساليب العملية. الأردن: دار المسيرة.

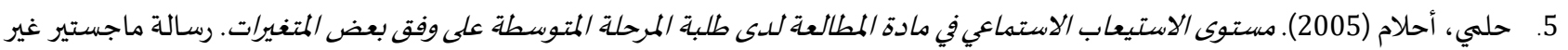
منشورة، كلية التربية بجامعة بغداد، العراق. 6. الخالدي، جمال (2013). درجة امتلاك معلمي التربية الإسالامية ومعلماتها لمفاهيم الاقتصاد المعرفي. مجلة الجامعة الإسلامية للدراسات التربوية والنفسياة: 1(21): 159 - 187. 7. خزعل، قاسم؛ مومني، عبد اللطيف (2010). الكفايات التعليمية لدى معلمات المرحلة الأساسية الدنيا في المدارس الخاصية في ضوء متغيرات المؤهل العلمي وسنوات الخبرة والتخصص. مجلم: مبلة جامعة دمشق: 3(10): 553- 592. 8. دهيم، سليمان (2019). ملدى امتلكك معلمات اللغة العربية في المبرحلة الابتدائية في الكويت للكفايات التدروليسية. مجلة القراءة والمعرفة: 207: .88-15 9. الرقيبات، رائد (2018). درجة /متلاك معملي التربية الإِلامية للكفايات المهنية التعليمية لطلاب الممحلة الثانوية من وجهة نظر مديري المدارس

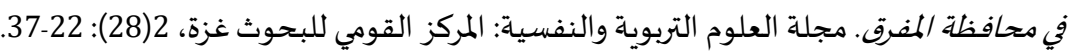
10. الزبون، حمدان (2014). درجة /متلاك معلمي التربية الإسلامية في الممحلة الثانوية لكفايات التدريس بلدولة الإمارات العربية المتحدة من وجهة

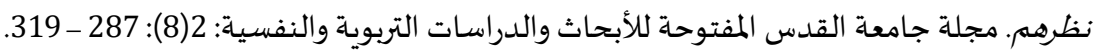
11. السعودي، خالد (2011). ملدى استخدلم معلمي التربية الإسالامية في محافظة الطفيلة للكفايات اللغوية. المجلة الأردنية في العلوم التربوية: 7(3): .302- 286 12. الشمري، عيد (2018). تقييم واقع /متلاك وممارسة معلمي الصفوف الأولى لاستراتيجيات التقويم البديل في / لممدارس التابعة لمنطقة الحائل.

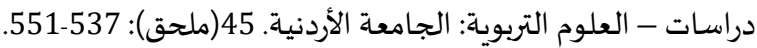

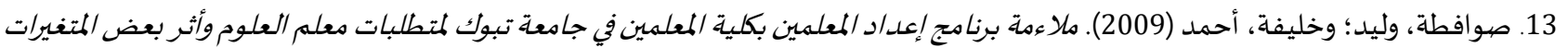
في أدائه المهني. مجلة رسالة الخليج العربي:114: 53-101. 


$$
\text { 14. طعيمة، رشدي؛ مناع، محمد (2001). تلدريس العببية في التعليم العامنظريات وتجارب. القاهرة: دار الفكر العربي. }
$$

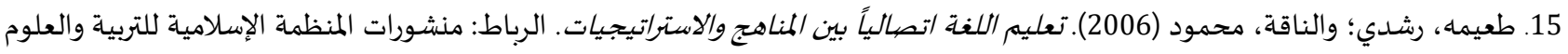

الثقافة (ايسيسكو).

16. عبيدات، ذوقان؛ عدس، عبد الرحمن؛ عبد الحق، كايد (2020). البحث العلمي مفهومة وأدواته وأساليبه. الأردن: دار الفكر للنشر والتوزيع.

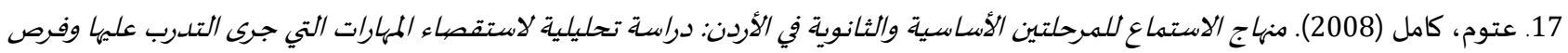
التدريب التي نالتها، والمهارات التي له يدرب عليها. المجلة الأردنية في العلوم التربوية: 4(3): 179-188.

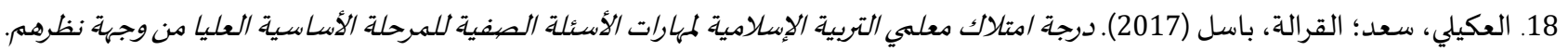

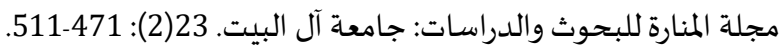

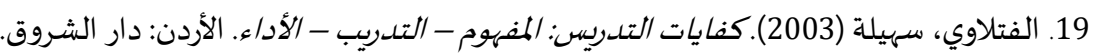

20. فيصل، ندى (2010). توظيف مهارة الاستماع في تلدريس التلاوة. مجلة كلية التربية للبنات: جامعة بغداد، 21 21(1): 49 - 62.

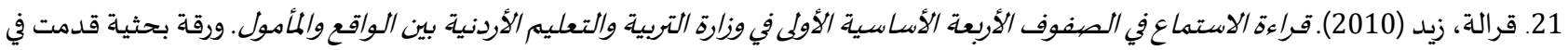

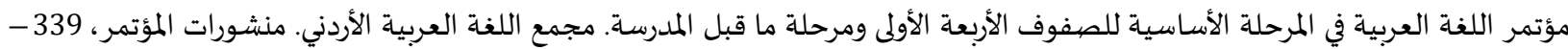
22. القرشي، وفاء (2018). مستوى تمكن معلمات اللغة العببية من أساليب تنمية مهارات الاستماع الناقـل لدى تلمين/ت الصفف الأول المتوسط بالعاصيمة المقلدسة. مجلة الجمعية المصرية للقراءة والمعرفة: 197: 197-214. 23. قورة، عليط؛ سنجى، سيد؛ أبو لبن، وجياء (2011). مهارات الاستماع اللازهة للتفوق الدراسية الماسية للدى طلبة جامعامعة طيبة "دراسة تحليلية". مجلة كلية التربية، جامعة المنصورة: 2 (75): 2 -61.

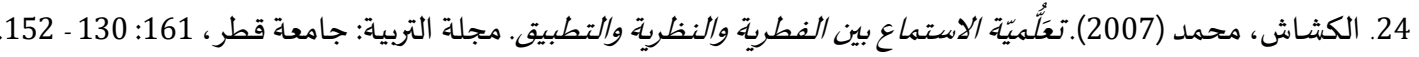
25. لافي، سعيد (2014). تعليم اللغة العربية المعاصرة. بيروت: عالم الكتب.

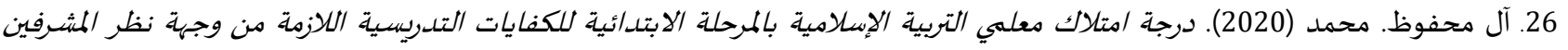
التويويين وقادة المدارس بالمملكة العربية السعودية. مجلة الجامعة الإسلامية للدراسات التربوية والنفسية: 28(1): 50 ـ 527.

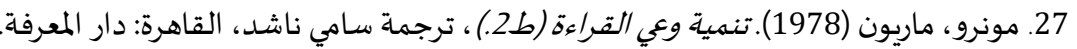

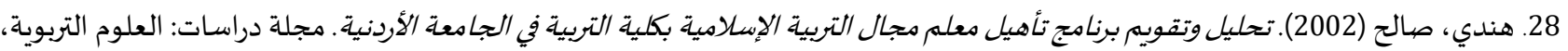
.88-63: 29 29. اليوسف، محمد (2017). درجة امتلاك معلمي التوبية الإسلامية في محافظة العاصهمة عمان لكفايات استخدلم التكنولوجيا الذكية في التعليمر.

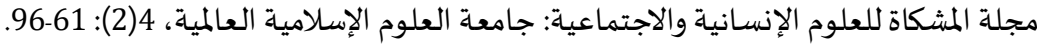

ثانياً: المراجع الأجنبية:

1. El-Naggar, Z. (2000). Spotlight on Primary English Education Resource (SPEER). Paper presented at the EgypTesol Second Annual Convention Cairo, Egypt.

2. Janusik, L. (2002). Teaching Listening: What do we do? What should we do? International Journal of Listening, $16(1): 5$ 40. https://doi.org/10.1080/10904018.2002.10499047

3. Swanson, C. G. (1986). Teachers as Listeners: an exploration. Paper presented at the 7th Annual Convention of the International Listening Association.

4. Wolvin, A. D. and Coakley, C. G. (2000) Listening (6 ${ }^{\text {th }}$.). New York, NY: McGraw Hill Education. 
المجلة الدولية للدراسـات التربوية والنفسية

\title{
The degree of possessing the minimum basic stage teachers' skills of listening to the Holy Quran in Amman
}

\section{Magdy Suleiman Al-Mashaleh}

College of Educational Sciences, Arab Open University, Jordan m_mashaleh@aou.edu.jo

\section{Issa Khalil Al-Hasanat}

College of Educational Sciences, Arab Open University, Jordan i_hasanat@aou.edu.jo

\author{
Received : 24/1/2021 Revised : 24/2/2021 Accepted : 13/3/2021 DOI : https://doi.org/10.31559/EPS2021.10.1.6
}

Abstract: The study aimed to identify the degree to which the lower elementary school teachers possess the skills of listening to the Holy Qur'an and to know the effect of the difference in educational experience and academic qualification on possessing these skills. The study population consisted of the female teachers who study this stage in the Directorate of Education of the Kasbah of Amman, and their number is (1723) teachers, and the sample was withdrawn from this community by the method of accidental inspection, and the sample consisted of (307) teachers who teach the lower elementary stage, during the school year 2020/2021. An achievement test was built as a tool to collect data from female teachers, and the study reached the following results: that female teachers possess a low level of total listening skills, and that both the skills of audible comprehension and audible taste were among the sub-skills of listening possessed by teachers with a medium degree, and that there are differences Statistical significance to the degree of female teachers 'possession of listening skills due to the variable of educational experience in favor of those with medium and high experience, and to the fact that the value of the practical significance - $\mathrm{Eta}^{2}$ - was low if it reached (0.04), as well as to the absence of statistically significant differences on the educational qualification variable of the teachers, or To variable interaction between educational experience and academic qualification.

The study was presented based on the results of a set of recommendations, including Paying attention to preparing more tests to measure the extent to which teachers possess the necessary educational skills.

Keywords: the degree of possessing teachers; teachers of the lower elementary stage; skill; listening; the skills of listening to the Holy Quran.

\section{References:}

1. 'bydat, Dwqan; 'ds, 'bd Alrhmn; 'bd Alhq, Kayd (2020). Albhth Al'lmy Mfhwmh Wadwath Wasalybh. Alardn: Dar Alfkr Llnshr Waltwzy'.

2. Al'kyly, S'd; Alqralh, Basl (2017). Drjt Amtlak M'lmy Altrbyh Aleslamyh Lmharat Alas'lh Alsfyh Llmrhlh Alasasyh Al'elya Mn Wjht Nzrhm. Mjlt Almnarh Llbhwth Waldrasat: Jam't Al Albyt. 23(2): 471-511.

3. 'twm, Kaml (2008). Mnhaj Alastma' Llmrhltyn Alasasyh Walthanwyh Fy Alardn: Drash Thlylyh Lastqsa' Almharat Alty Jra Altdrb 'lyha Wfrs Altdryb Alty Naltha, Walmharat Alty Lm Ydrb 'lyha. Almjlh Alardnyh Fy Al'lwm Altrbwyh: 4(3): 179188.

4. Albdah, Fhd (2006). Mda Twfr Alkfayat Alt'lymyh Lda M'lmy Altrbyh Aleslamyh Fy Alhlqh Althanyh Mn Almrhlh Alabtda'yh Balmmlkh Al'rbyh Als'wdyh. Rsalt Majstyr Ghyr Mnshwrh, Jam't Sn'a', Alymn. 
5. Albdry, Almhdy (1990). Mharat Alastma' Lda Tlab Dr Alm'lmyn Walm'lmat, Drash Tqwymyh. Rsalt Dktwrah Ghyr Mnshwrh, Klyt Altrbyh, Jam't Almnswrh.

6. Albshyr, Akrm (2005). Mharh Alastma' Fy Mnhaj Allghh Al'rbyh Lsfwf Alhlqh Althanyh Mn Almrhlh Alasasyh Fy Alardn: Drash Thlylyh. Almjlh Altrbwyh: 20 (77): 99 - 127.

7. Dhym, Slyman (2019). Mda Amtlak M'lmat Allghh Al'rbyh Fy Almrhlh Alabtda'yh Fy Alkwyt Llkfayat Altdrysyh. Mjlt Alqra'h Walm'rfh: 207: 15-88.

8. Alftlawy, Shylh (2003). Kfayat Altdrys: Almfhwm - Altdryb - Alada'. Alardn: Dar Alshrwq.

9. Fysl, Nda (2010). Twzyf Mharh Alastma' Fy Tdrys Altlawh. Mjlh Klyh Altrbyh Llbnat: Jam't Bghdad, 21(1): 49 - 62.

10. Hlmy, Ahlam (2005). Mstwa Alasty'ab Alastma'y Fy Madh Almtal'h Lda Tlbt Almrhlh Almtwsth 'la Wfq B'd Almtghyrat. Rsalt Majstyr Ghyr Mnshwrh, Klyt Altrbyh Bjam't Bghdad, Al'raq.

11. Hndy, Salh (2002). Thlyl Wtqwym Brnamj Tahyl M'lm Mjal Altrbyh Aleslamyh Bklyh Altrbyh Fy Aljam'h Alardnyh. Mjlt Drasat: Al'lwm Altrbwyh, 29(2): 63-88.

12. Aljlad, Majd (2007). Tdrys Altrbyh Aleenslamyh: Alass Alnzryh Walasalyb Al'mlyh. Alardn: Dar Almsyrh.

13. Alkhaldy, Jmal (2013). Drjt Amtlak M'Imy Altrbyh Aleslamyh Wm'lmatha Lmfahym Alaqtsad Alm'rfy. Mjlt Aljam'h Aleslamyh Lldrasat Altrbwyh Walnfsyh: 1(21): 159 - 187.

14. Khz'el, Qasm؛ Mwmny, 'bd Alltyf (2010). Alkfayat Alt'lymyh Lda M'lmat Almrhlh Alasasyh Aldnya Fy Almdars Alkhash Fy Dw' Mtghyrat Almehl Al'lmy Wsnwat Alkhbrh Waltkhss. Mjlt Jam't Dmshq: 3(10): 553- 592.

15. Alkshash, Mhmd (2007). T'lumyh Alastma' Byn Alftryh Walnzryh Walttbyq. Mjlt Altrbyh: Jam't Qtr, 161: 130 - 152.

16. Lafy, S'eyd (2014). T'elym Allghh Al'rbyh Alm'asrh. Byrwt: 'alm Alktb.

17. Al Mhfwz. Mhmd (2020). Drjt Amtlak M'lmy Altrbyh Aleslamyh Balmrhlh Alabtda'yh Llkfayat Altdrysyh Allazmh Mn Wjht Nzr Almshrfyn Altrbwyyn Wqadt Almdars Balmmlkh Al'rbyh Als'wdyh. Mjlt Aljam'h Aleslamyh Lldrasat Altrbwyh Walnfsyh: 28(1): 50 - 527.

18. Mwnrw, Marywn (1978). Tnmyh W'y Alqra'h (T2.), Trjmt Samy Nashd, Alqahrh: Dar Alm'rfh.

19. Qralh, Zyd (2010). Qra't Alastma' Fy Alsfwf Alarb'h Alasasyh Alawla Fy Wzart Altrbyh Walt'lym Alardnyh Byn Alwaq' Walmamwl. Wrqh Bhthyh Qdmt Fy M'tmr Allghh Al'rbyh Fy Almrhlh Alasasyh Llsfwf Alarb'eh Alawla Wmrhlh Ma Qbl Almdrsh. Mjm' Allghh Al'rbyh Alardny. Mnshwrat Alm'tmr, 339 - 382.

20. Alqrshy, Wfa' (2018). Mstwa Tmkn M'lmat Allghh Al'rbyh Mn Asalyb Tnmyt Mharat Alastma' Alnaqd Lda Tlmydat Alsf Alawl Almtwst Bal'asmh Almqdsh. Mjlh Aljm'yh Almsryh Llqra'h Walm'rfh: 197: 197-214.

21. Qwrh, 'lyt; Snja, Syd; Abw Lbn, Wjyh (2011). Mharat Alastma' Allazmh Lltfwq Aldrasy Lda Tlbt Jam't Tybh "Drash Thlylyh". Mjlt Klyt Altrbyh, Jam't Almnswrh: 2(75): 2 -61.

22. Alrqybat, Ra'd (2018). Drjt Amtlak M'mly Altrbyh Aleenslamyh Llkfayat Almhnyh Alt'lymyh Ltlab Almrhlh Althanwyh Mn Wjht Nzr Mdyry Almdars Fy Mhafzt Almfrq. Mjlt Al'lwm Altrbwyh Walnfsyh: Almrkz Alqwmy Llbhwth Ghzh, 2(28): 2237.

23. Als'wdy, Khald (2011). Mda Astkhdam M'lmy Altrbyh Aleslamyh Fy Mhafzt Altfylh Llkfayat Allghwyh. Almjlh Alardnyh Fy Al'lwm Altrbwyh: 7(3): 286 - 302.

24. Alshmry, 'yd (2018). Tqyym Waq' Amtlak Wmmarsh M'lmy Alsfwf Alawla Lastratyjyat Altqwym Albdyl Fy A Lmdars Altab'h Lmntqh Alha'l. Drasat - Al'lwm Altrbwyh: Aljam'h Alardnyh. 45(Mlhq): 537-551.

25. Swafth, Wlyd; Wkhlyfh, Ahmd (2009). Mla'mh Brnamj E'dad Alm'lmyn Bklyh Alm'lmyn Fy Jam't Tbwk Lmttlbat M'lm Al'lwm Wathr B'd Almtghyrat Fy Ada'h Almhny. Mjlt Rsalt Alkhlyj Al'erby:114: 53-101.

26. T'ymh, Rshdy; Mna', Mhmd (2001). Tdrys Al'rbyh Fy Alt'lym Al'am Nzryat Wtjarb. Alqahrh: Dar Alfkr Al'rby.

27. T'ymh, Rshdy; Walnaqh, Mhmwd (2006). T'lym Allghh Atsalyaan Byn Almnahj Walastratyjyat. Alrbat: Mnshwrat Almnzmh Aleslamyh Lltrbyh Wal'lwm Althqafh (Aysyskw).

28. Alywsf, Mhmd (2017). Drjt Amtlak M'lmy Altrbyh Aleslamyh Fy Mhafzt Al'asmh 'Eman Lkfayat Astkhdam Altknwlwjya Aldkyh Fy Alt'lym. Mjlh Almshkah Ll'lwm Alensanyh Walajtma'yh: Jam't Al'lwm Aleslamyh Al'almyh, 4(2): 61-96.

29. Alzbwn, Hmdan (2014). Drjt Amtlak M'lmy Altrbyh Aleslamyh Fy Almrhlh Althanwyh Lkfayat Altdrys Bdwlt Alemarat Al'rbyh Almthdh Mn WjhtNzrhm. Mjlt Jam't Alqds Almftwhh Llabhath Waldrasat Altrbwyh Walnfsyh: 2(8): 287 - 319.

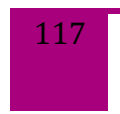

